\title{
NOVEL DESIGN AND MODELING OF SHUTTER VALVES FOR CAMLESS ENGINES
}

Muhammad Arsalan Jalees Abro Master's Student, Department of Mechatronics Engineering, Institute of Information Technology. Jamshoro (Pakistan) E-mail: arsalan_jalees@hotmail.com

Saifullah Samo

Department of Mechanical Engineering, Mehran UET. Jamshoro (Pakistan) E-mail: saifullah.samo@faculty.muet.edu.pk

Dur Muhammad Pathan Department of Mechanical Engineering, Mehran UET. Jamshoro (Pakistan) E-mail: dur.pathan@faculty.muet.edu.pk

Irfan Ahmed Halepoto Department of Electronic Engineering, Mehran UET. Jamshoro (Pakistan) E-mail:irfan.halepoto@gmail.com

Recepción: 05/03/2019 Aceptación: 27/03/2019 Publicación: 17/05/2019

\section{Citación sugerida:}

Abro, M. A. J., Samo, S., Pathan, D. M. y Halepoto, I. A. (2019). Novel Design and Modeling of Shutter Valves for Camless Engines. 3C Tecnología. Glosas de innovación aplicadas a la pyme. Edición Especial, Mayo 2019, pp. 518-533. doi: http://dx.doi. org/10.17993/3ctecno.2019.specialissue2.518-533

\section{Suggested citation:}

Abro, M. A. J., Samo, S., Pathan, D. M. \& Halepoto, I. A. (2019). Novel Design and Modeling of Shutter Valves for Camless Engines. 3C Tecnología. Glosas de innovación aplicadas a la pyme. Special Issue, May 2019, pp. 518-533. doi: http://dx.doi. org/10.17993/3ctecno.2019.specialissue2.518-533 


\section{ABSTRACT}

For the intake of air fuel mixture and exhaust of gases camshaft operated valves are mounted on the cylinder head. In this paper, we have proposed a novel physical model of a shutter valve to replace the traditional camshaft operated valve resulting in a camless four-stroke engine. The lift control for the opening and closing of the intake and exhaust valves are monitored traditionally by a camshaft which is a mechanical component having a fixed shape. A camless engine replaces the camshaft by allowing the control of valves through the Electronic Control Unit (ECU). The already developed valves have limitations in terms of lift, life expectancy or higher costs. This research work proposes a novel shutter valve design instead of a poppet valve for intake and exhaust of fourstroke engines. These valves are then operated directly by an ECU and controlled through pulse width modulation. The proposed variation in shutter valve design optimally adjusts and controls the fuel intake amount and the flow of exhaust gases in and out of the cylinder respectively. The opening of the valve can be set to maximum or at the desired angle so that the engine can run according to the driver's requirement. The novel design of the shutter valve will reduce the engine cost and will improve the fuel economy. At the same time, providing complete control to the driver's performance preferences.

\section{KEYWORDS}

Camless engine, Camshaft engine, Four-stroke engine, Shutter valve, Poppet valve. 


\section{INTRODUCTION}

The basic concept of an engine is to convert one form of energy into mechanical energy and use that energy to do work. There are different types of engines available but in this work, the focus will be given to four-stroke engines and their performance factors. Since the invention of engines, society has upgraded a lot of its norms. These engines are used in various types of transport models like aircraft, ships, trains and road vehicles. For each of these types, the engine is modified accordingly. Different vehicles are suitable for different ranges of torque to be produced. The engine is built according to the environment where it is to be used. Either a large load is to be carried along which requires heavy torque based engines or quick mode of transportation is the key focus. In the latter case, high speed producing engines are required such as in racecars. There are cases where engines with both power and speed play a vital role. The vehicles have become the most important part of our socio-economical activities which either run on petrol, diesel or other forms of non-renewable fuels. The increasing number of vehicles on road is stressing the non-renewable fuel resources as there hasn't been any major discovery since last two decades and reserves are depleting quickly. On the other side, burning the fuels produce pollutants which are destroying the environment. To overcome these issues, the researchers are working on different alternatives to power up the engines by making internal and external design changes for economical purposes and reducing carbon emission at the same time.

The already developed valves have limitations in terms of lift, life expectancy or higher costs. This research work proposes a novel shutter valve design instead of a poppet valve for intake and exhaust of four-stroke engines. These valves are then operated directly by an ECU and controlled through pulse width modulation. In this paper, we are proposing the design variations in shutter valve to optimally adjust and control the fuel intake amount and the flow of exhaust gases in and out of the cylinder respectively. The opening of the valve can be set to maximum or at the desired angle so that the engine can run according to the driver's requirement. 
The valid scope of this research is to replace the traditionally used camshaft based poppet valves with a suitable model of a shutter valve which eliminates the requirement of a cam. The intention of the model designed is to increase the overall economy of the engines and to reduce the rate of production of exhaust gases by controlling the amount of fuel to be burnt.

The remainder of the paper is organized as under; in Section 2 a technical comparison between the cam and camless engine is made. The working of IC engine is discussed thoroughly. In response to existing poppet valve, the novel prospect of shutter valve is discussed in Section 3. In Section 4, a novel model of shutter valve for camless engines is proposed, designed and modelled. Section 5 concludes the paper and highlights future research potential.

\section{CAM VS CAMLESS ENGINES}

According to Heywood (1988), the working of an internal combustion engine requires a proper balance of air and fuel intake and with that, proper timings are required to allow the mixture to flow in the engine and the waste gases to flow out of the engine. The general structure of the IC engine is shown in Figure 1. According to Roan (1959), in this era, most of the vehicles are equipped with a mechanical overhead camshaft. According to Siewert (1971), the idea of varying the valve timing in a spark ignition engine for improved performance, better fuel economy, improved power, improved turbocharging, efficient emission control and other performance factors are under consideration since last century. The most basic type of internal combustion (IC) engines is four stroke engines. The piston covers four stages called strokes to cover a complete cycle. The movement of the piston from TDC (top dead center) to BDC (bottom dead center) or vice versa is called a stroke. These stokes are named as intake, compression, power and exhaust respectively. 


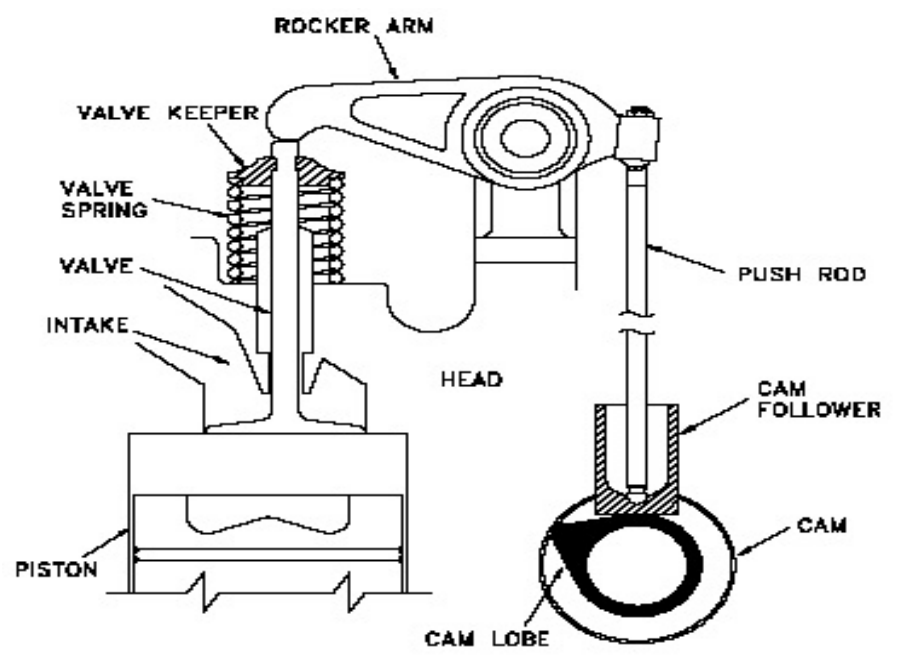

Figure 1. General structure of the IC engine.

In this paper, we have concentrated on the intake and exhaust stroke. In an IC engine, the intake of the fuel mixture and the exhaust of the different gases from the cylinder are controlled by the intake and exhaust valves respectively. The cylinder head has an intake opening and an exhaust opening so that the flow of the fluids can enter or leave the cylinder that is before and after the combustion process for a required cycle. In a particular cycle, both valves operate only once. As the cycle begins, the intake valve opens up that is in the first stroke and at the end of the cycle, at the last stoke, the exhaust valve opens up in order to release the exhaust gases.

Traditionally, the types of valves used are the poppet valves. These valves are operated by a camshaft which is a mechanical component having a fixed shape of lobes. The cam operates the pushrod or lifter which operates the rocker arm in order to control the opening and the closing of the valves as shown in Figure 2. One of the drawbacks of a cam is that the timing of the valves remains fixed for a predetermined driving functionality. The duration of the opening and the closing of the intake and exhaust valves are constant and depend on the shape of the camshaft lobe. At increased revolutions per minute (RPM), the engine requires a higher amount of air-fuel mixture to pass through the intake valve. Due to the fixed period of time for the opening of the intake valves, the air-fuel 
mixture can blow out of the cylinder and return to the intake manifold thus creating a state of blowback.

Though a mechanism known as variable valve timing does change the timing according to the ignition requirements in an Engine Control Unit (ECU) based engines that is again for limited performance ranges. In a camless engine, the cam, pushrod/lifter and rocker arm are removed. These alterations not only reduce the size and the weight of the engine but also offer flexible synchronization of valve operation at particular RPM. The valves in a camless engine are directly controlled by the ECU which eliminates the need for a timing belt to synchronize the opening and the closing of the valves with the strokes of the pistons.

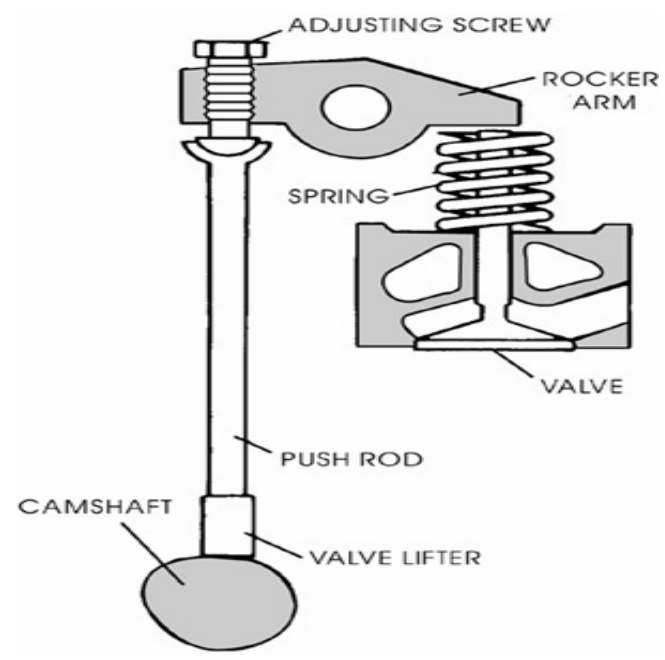

Figure 2. Operation of a Poppet value through a cam.

The concept of the camless engine valvetrain system has been revolving since over the last decade. Though the potential has not yet met the high-performance criteria. According to Postrioti, Battistoni, Foschini and Flora (2009) as compared to conventional RPM ranges, the range was limited to much lower RPM values. The valves in a camless engine are controlled electronically through the signals from the ECU and a required control circuit according to the valve's design. These values can be remapped by mapping the ECU or by altering the programming of the control circuit. A camless engine thus becomes more suitable and efficient as compared to the camshaft based engine. It also becomes more economical due 
to the reduction in the size and weight of the engine. With the reduction in size, as the engine bay is reduced in height, the overall dynamics of the vehicle can be improved which results in faster accelerations. Other than this, the added cost of the mechanical components is reduced which improves the manufacturing cost.

\section{SHUTTER VALVES VS POPPET VALVES}

Current research in the field of camless engines is focused upon poppet valves. They have controlled either through electro-hydraulic (Nam, Cho, Park, \& Choi, 2017), electro-pneumatic or electro-magnetic circuits (Chen, Chang \& Fan, 2019). The authors Tai, Stubbs and Tsao (2001) have developed electromagnetic valves by using grey box approach through which system identification and mathematical modelling was performed. The study states experimental results for the quiet seating issue of the valves. They further recorded the error and timing of the valves through feedback. As an extension of Tai, et al., (2001), the authors Gillella and Sun (2011) have developed an improved version of a camless-valve actuation system which included an internal feedback system to monitor the working and the timings of the valves.

Current work has been carried out on camless engines using solenoid valves (Liu \& Chang, 2011) but still, there is a dire need to further work on the lifting and the proper closing of the valves (Anderson, Tsao \& Levin 1998). The other replacement of the mechanical camshaft available in the literature is the electrohydraulic valve system (Sun \& Kuo, 2010). This system has limits in terms of practical implementation at low RPM. According to Haas (2010), an electrohydraulic valve system (EHVS) based control system was developed which utilizes the fixed volume of oil for the lift of the valves which limits the maximum valve lift as compared to the cam profile. The intended research controls the valves through electromagnetic circuit. The poppet valves have their limitations in terms of use. They have limited lift which matters especially at higher RPMs. The lift is an essential factor while considering the efficiency and the power output of an engine. Due to limited lift, at higher RPMs, the required fuel mixture does 
not reach the cylinder thus resulting in low engine performance. In the designed shutter valve, the lift factor isn't involved. Instead of the lift factor, the shutter valves open radially which can be adjusted using a different number of blades in a shutter valve. Another factor such as the heavy springs used in the poppet valves in order to keep the valves properly closed at high pressures, produce a delay in the lift's response time and also results in a higher resistance when it comes to operating them at the precise moment. This process is detailed in Figure 3.

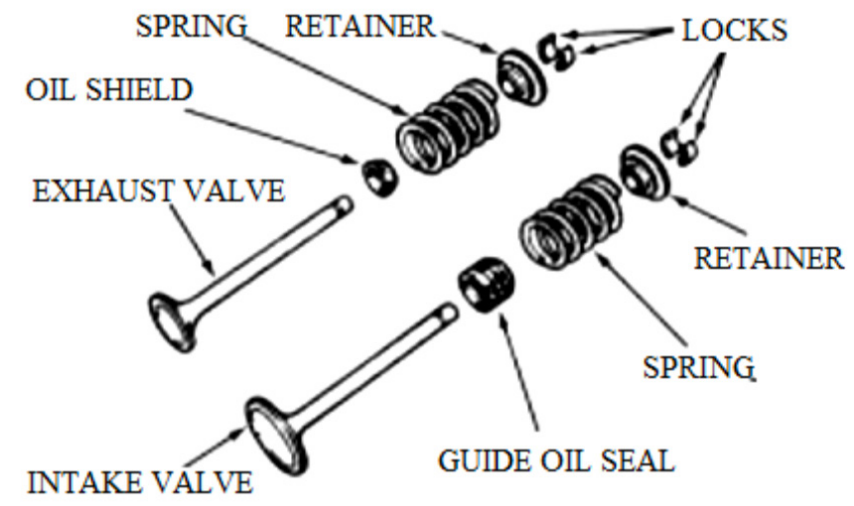

Figure 3. Components of Poppet valves.

Poppet valves in a cam based engine can easily be operated as the driving force is a heavy mechanical component but when it comes to an electronically controlled engine, these can only be when provided with a high-power supply. The shutter valves operate on a simple mechanism which eliminates the use of heavy springs thus clearing the error of a delay factor and the loss of power from the crankshaft which results in an efficient system of control. When using the poppet valves, the pistons are affected by cavities which form over time as the engine is used. The cavity thus results in a dimpled interior within the combustion chamber. Due to these cavities, uneven flame propagation takes place. As the cavities increase in depth, some air-fuel mixture is left unburnt leaving the car run rich and results in uneconomic fuel combustion. This also results in the loss of energy which results in the lower performance of the engine.

In the proposed shutter valve, cavities will not be formed due to the mode of operation and the shape of the shutter valve. This will eliminate the drawbacks 
of loss of energy, engine running rich and out of order. Other than these factors, poppet valves take up more space in an engine bay and increase the weight of the engine as compared to shutter valves. Both of these factors reduce the efficiency of the engine. By further reducing the size of the engine, the vehicle's aerodynamics can be enhanced which results in an increase in the performance of the vehicle. The efficiency is also increased by the reduction in weight due to the poppet valves and the required components to operate them. This will slightly reduce the production cost of the engine. The electromagnetic valves based camless engines were modelled but were limited in terms of lifting and the proper closing of the valves (Lino, et al., 2016). Though improvements have been made since the introduction of this method still there is a lot of work required to reach the optimum results. An engine based on electro-pneumatic valves was designed and nowadays it is in use for testing purpose. As per observations of various researchers, the valves are expensive and there are lots of chances of fluid leakage at higher RPM but these observations need proper verification and experimental setups to validate.

The purpose of this research is to propose a novel approach towards the camless engines. For this purpose, the diaphragm shutters are used as shutter valves. These shutter valves will reduce the loses carried out by the previous systems, by reducing the use of noisy components and the risk of wear and expensive maintenance. The implemented model of shutter valves will allow the separate monitoring and easy tuning which eliminates the hectic process of altering the camshaft of an engine.

\section{THE PROPOSED NOVEL DESIGN OF SHUTTER VALVE}

Figure 4 is the novel proposed design of shutter valve's front view. The valve consists of two circular disks, 6 blades in between which interlock with each other, and a slider to operate the blades. 


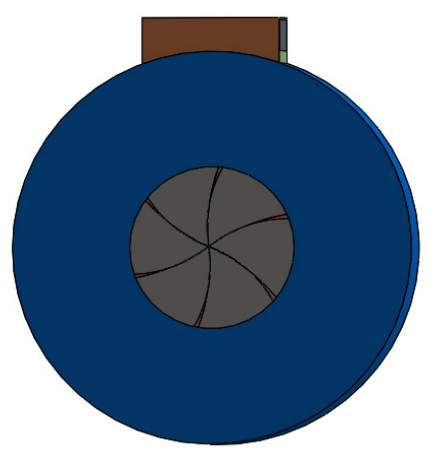

Figure 4. The proposed novel design of shutter valve.

The interlocking mechanism is present so that the blades may not get bent out of shape when affected by heavy pressures. At the instance of combustion, the pressure in the cylinder rises. In the shutter valve, as compared to the poppet valve, the spring is not required for the linear operation of the valve. The pressure developed during the power stroke, it is necessary for the intake valves to remain closed as well as during the compression and the exhaust stroke. On the other hand, the exhaust valves sustain high pressures during the compression and the power stoke. So, this shape of the shutter valves keeps the blades in fixed shape and remains tightly closed. This is shown in Figure 5.

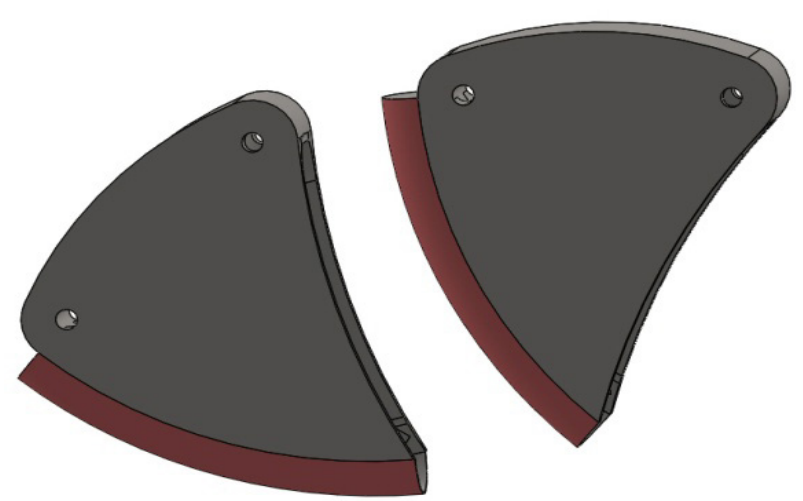

Figure 5. Interlocking blades of shutter valve.

In a normal state, when the engine is powered off, the valves remain closed. The bar on the shutter valve assists the opening and closing of the valve. The ECU monitors the position of each of the pistons separately by using the crankcase 
sensor which regulates the voltage signal and is transmitted to the control circuit. When the control circuit signal is activated due to defined pulse timing, the magnetic contact becomes energized and attracts the rod towards itself as shown in Figure 6.

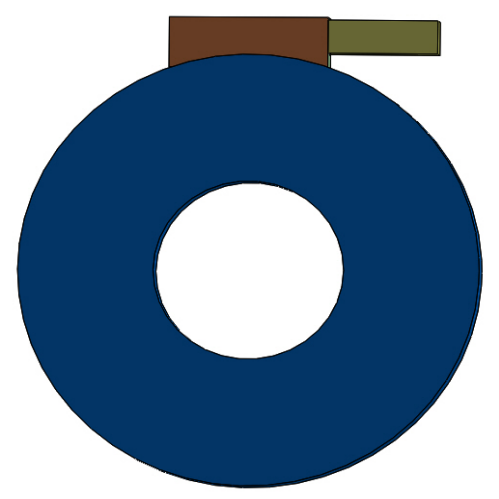

Figure 6. Opening of shutter valve during the high state of the control circuit.

When the contact is closed, the operating bar rotates the slider. As the slider rotates, the blades rotate allowing them to open up or close. This operation is carried out separately for allowing either the air-fuel mixture to enter the cylinder or the exhaust gases to leave the cylinder. For both the intake and the exhaust operations, different configuration of the control circuit is required in order to adjust the operating cycle of the shutter valves. The shutter valves are enclosed within the casing structure through which the blades cooling mechanism is achieved. At high temperatures, the blades will get deformed and to avoid that both the material and the cooling of the blades is essential.

Another feature of these shutter valves is that the performance output is adjustable. Depending on the drive requirements, the opening and closing diameter of the shutter valves can be adjusted. There are different levels upon which the operating contact of the control circuit is tuned. Potentially there can be different positions of operating contact ranging from nearest to farthest. Fixing the contact at the farthest end will result in the complete opening of the valve and adjusting it to the nearest operating end will result in a narrow opening of the intake shutter valve. The unburnt fuel will return in the tank to be utilized in the next cycle. Through the change in the opening, the working of the engine will either produce an 
economic run or a power drive. On the operating bar of the shutter valves, a spring is mounted as shown in Figure 7.

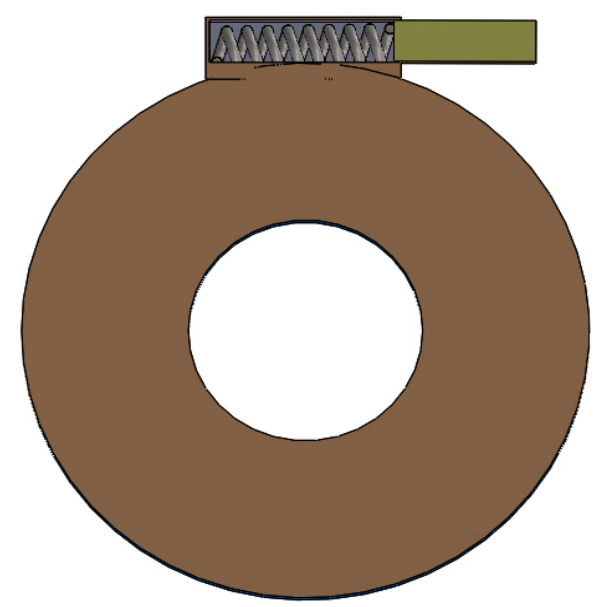

Figure 7. Cross-sectional view of shutter valve during blades opening.

The functionality of the spring is to keep the valves closed at all times and assist in the closing of the valve once the control circuit switches from on state to an off state. Normally when a magnetic circuit switches to the off state, there is a delay time due to the demagnetizing factor of the attracting metals. The purpose of this spring is to reduce the delay time and allow fast and easy switching of the shutter valves. This proposed design alteration of shutter valves will save the vehicles fuel consumption, resulting in a more economical model. This economy lends a hand in reducing the nitrogen oxide emissions (NOx).

\section{CONCLUSION}

Camless engines are emerging research area and its true potential is yet to be explored in the field of automobiles. In this paper, the existing camless engines are thoroughly studied. On the detailed study, a novel model of shutter valve for camless engines is proposed, designed and modeled for fuel efficiency, light weight, cost efficiency, variable valve control, aerodynamics and environmental friendly by reducing NOx emission. The proposed shutter valve is easy and maintainable and allows the industries to adapt without any hectic processes or heavy upgrades. 
The modeled design of shutter valve based camless engines will revolutionize the automobile industry by opening the gates of the novel concept of hybrid economical sports cars. This can be a new venture for automobile industries to explore, invest and produce a high grossing production line of futuristic vehicles.

\section{ACKNOWLEDGEMENTS}

Authors are highly grateful to Mehran University of Engineering and Technology, Jamshoro, Pakistan, for the support, the necessary laboratory facilities and comfortable research environment. The first author is highly in debt of Engr. Muhammad Sharif Jamali for his support and guidance in understanding the designing tools. Special thanks to Amjad Hussain, owner of Hi-Tech Motors Hyderabad, Pakistan for sharing his technical automobile knowledge. 


\section{REFERENCES}

Anderson, M. D., Tsao, T. G. \& Levin, M. B. (1998). Adaptive lift control for a camless electro hydraulic valvetrain. SAE International, pp. 1473-1480. doi: http:/ /dx.doi.org/10.4271/981029

Chen, H., Chang, S. \& Fan, A. (2019). Model-Based Control of Electromagnetic Valve Actuators for Engine Speed Control. International fournal of Automotive Technology, 20(1), pp. 127-135. doi: http://dx.doi.org/10.1007/s12239-0190012-0

Gillella, P. \& Sun, Z. (2011). Design, modeling, and control of a camless valve actuation system with internal feedback. ASME Transactions on Mechatronics, 16(3), pp. 527-539. doi: http://dx.doi.org/10.1109/TMECH.2010.2045656

Haas, M. (2010). UniAir-the first fully-variable, electro-hydraulic valve control system. In $9^{\text {th }}$ Schaeffler Symposium Book.

Heywood, J. B. (1988). Internal Combustion Engine Fundamentals. U.S.A.: McGraw-Hill.

Lino, P., Maione, G., Saponaro, F., Deng, J. \& Li, K. (2016). Identification of solenoid valve dynamics in a variable valve timing system. In 2016 UKACC $11^{\text {th }}$ International Conference on Control, pp. 1-6. doi: http://dx.doi. org/10.1109/CONTROL.2016.7737570

Liu, L. \& Chang, S. (2011). Improvement of valve seating performance of engine's electromagnetic valvetrain. Mechatronics, 21(7), pp. 1234-1238. doi: http://dx.doi.org/10.1016/j.mechatronics.2011.08.002

Nam, K., Cho, K., Park, S. S. \& Ghoi, S. (2017). Design and Performance Evaluation of an Electro-Hydraulic Camless Engine Valve Actuator for Future Vehicle Applications. Sensors, 17(12), pp. 2940-2953. doi: http:// dx.doi.org/10.3390/s17122940.

Nielsen, A. G. (n.d.). Free valve technology. Retrieved from http://www. freevalve.com/technology/freevalve-technology/ 
Postrioti, L., Battistoni, M., Foschini, L. \& Flora, R. (2009). Application of a fully flexible electro-hydraulic camless system to a research SI engine. In SAE 9th International Conference on Engines and Vehicles (ICE2009). doi: http: / / dx.doi.org/10.4271/2009-24-0076

Roan, H. A. (1959). U.S. Patent No. 2,880,712. Washington, DC: U.S. Patent and Trademark Office.

Siewert, R. M. (1971). How individual valve timing events affect exhaust emissions. SAE International, pp. 2156-2174.

Sun, Z., \& Kuo, T. W. (2010). Transient control of electro-hydraulic fully flexible engine valve actuation system. IEEE Transactions on Control Systems Technology, 18(3), pp. 613-621. doi: http://dx.doi.org/10.1109/TCST.2009.2025188

Tai, G., Stubbs, A., \& Tsao, T. G. (2001). Modeling and controller design of an electromagnetic engine valve. In IEEE Proceedings of the American Control Conference, 4, pp. 2890-2895. doi: http://dx.doi.org/10.1109/ACG.2001.946339 